\title{
Fat Reduction and Replacement by Olive Oil in Bologna Type Cooked Sausage. Quality and Nutritional Aspects
}

\author{
Fatima Beiloune, Tomas Bolumar, Stefan Toepfl, Volker Heinz \\ Department of Process Technologies, German Institute of Food Technologies, \\ Quakenbrueck, Germany \\ Email: tbolumar@hotmail.com
}

Received 17 December 2013; revised 17 January 2014; accepted 24 January 2014

Copyright (C) 2014 by authors and Scientific Research Publishing Inc.

This work is licensed under the Creative Commons Attribution International License (CC BY). http://creativecommons.org/licenses/by/4.0/

\section{Open Access}

\begin{abstract}
Eight different types of Bologna type cooked sausages apart from the control were produced in order to reduce the fat content $(15 \%, 30 \%, 45 \%)$, replace the animal fat by olive oil $(3 \%, 6.5 \%$ and $10 \%$ ) as well as concomitant reduction and replacement of animal fat (30\% of fat reduction with $2 \%$ of olive oil as an animal fat replacer). Quality attributes such as texture, water binding and color were monitored. Texture and water binding of fat reduced and fat replaced samples were quite similar to the control while color was strongly affected by the fat reduction and replacement. Fat reduction led to a redder cooked sausage and the addition of olive oil to a more yellow product. Chemical analysis revealed no major changes among samples apart from protein and fat content and fatty acid profile. Noteworthy, cooked sausage with more than $6.5 \%$ of olive oil achieved the World Health Organization's recommendation on the nutritional fat index ((polyunsaturated + monounsaturated)/saturated fatty acid $\geq 2$ ) which is very relevant to the development of healthier formulations. Cooked sausages with $45 \%$ of fat reduction and $30 \%$ fat reduced with $2 \%$ of olive oil were considered as the best by the panelists, which in addition had a balanced nutritional content by a lower caloric content. We concluded that fat reduction (up to 45\%) and replacement (up to 10\%) are possible with acceptable sensory quality and improved nutritional composition. When replacing animal fats by plant oils, the color of the product, which has a strong influence on the sensory acceptability of Bologna type cooked sausages, is affected. Therefore it must be controlled for a proper product development of meat products containing vegetable oils.
\end{abstract}

\section{Keywords}

Fat Reduction; Fat Replacement; Fatty Acid Profile; Olive Oil; Meat Products; Bologna Type Cooked Sausage 


\section{Introduction}

Meat consumption has increased during the last decades although different trends can be observed in different countries in this way. In developing countries the meat consumption has been documented to rise $(+1.5 \%)$ while in developed countries a decrease $(-0.5 \%)$ has been observed [1]. At the same time, consumers' habits have changed; the current consumption trend is towards lean meat, nevertheless a higher consumption of meat products as convenience products has also been reported (processed meat $+4 \%$ ) [2]. Meat products like Bologna type cooked sausage are very popular in Europe. Because of their appeal to the consumer and affordable cost, they constitute an important product in the diet of many families, therefore alternatives to improve the nutritional composition of the fat fraction in Bologna type cooked sausage can render in effective strategies for better fat ingestion of the population.

More than $60 \%$ of all reported diseases in modern industrial countries are said to have the origin from malnutrition related to low vitamin intake, high caloric food consumption and high consumption of fat and sugar [3]. Health Organizations have recommended a fat reduction in order to achieve the recommendations (30\% total fat, $<10 \%$ saturated, $\leq 300 \mathrm{mg}$ /day cholesterol). Moreover, worldwide organizations like the World Health Organization (WHO), which also is supported by the Council for the European Commission, are calling for the integration of health policy with agriculture and production in order to improve eating habits and correct the imbalances [4] [5].

Cardiovascular diseases are the leading causes of death among men and women in Europe [6], which means that cardiovascular diseases are responsible for nearly half of the European deaths, causing more than 4.35 million of deaths in the 52 States Members in the European Region of the WHO and more than 1.9 million of deaths in the European Community. Cancer is the second leading cause of death [7]. Both these diseases are related to excess fat intake and imbalance lipid profile on the diet. In this sense, olive oil has been associated with a decrease in overall and cardiovascular mortality [8]. What is more, cumulative evidence suggests that olive oil may have a profound influence on health, specially on cardiovascular risk factors [9]-[11].

Some researches support the concept of the important role that saturated fat plays in cancer promotion [12], and strong evidences have been found for a relation among obesity and total fat intake and the incidence of certain types of cancers. There is in fact a significant correlation between total fat intake and the risk of cancer. But also cholesterol accumulation may cause prostate cancer [13], an inverse association between on-treatment LDL-cholesterol and incident cancer has been found [14] as well as an inverse association of serum cholesterol with many cancers [14]-[16]. On the basis of these facts, it seems necessary to develop meat products with a healthier fat fraction.

In the present paper, the fat content of the popular Bologna type cooked sausages has been reduced and olive oil has been used for replacing saturated animal fat. Main quality traits, such as water holding capacity, texture and color, have been monitored together with compositional determination to verify fat reduction and analyze the improved fatty acid profile. Sensory analysis has been carried out to determine the acceptability of the reduced and animal fat replaced Bologna type cooked sausages. Taking everything into account, the present paper aims at designing a product that satisfies the consumers and does not jeopardize their health.

\section{Material and Methods}

\subsection{Sausage Formulation and Processing}

Fresh post-rigor pork meat and fat were obtained from a local slaughterhouse. The formulations of the different cooked sausage produced can be visualized in the Table 1. The following meat ingredients according to GEHA quality standard were used: meat trimmings (standard PII: low fat meat from shoulder with approximate composition of $73 \%$ water, $8 \%$ fat, $17.5 \%$ pure muscle protein (PMP) and $1.5 \%$ connective tissue protein (CTP)), cheeks (standard PVI, with approximate composition of $40 \%$ water, $50 \%$ fat, $7.0 \%$ PMP and $1.5 \%$ CTP) and fatty tissue (PIX fat from shoulder with approximate composition of $25 \%$ water, $70 \%$ fat, $2.5 \%$ PMP and $2.5 \%$ CTP). Each recipe also contained $18 \mathrm{~g} / \mathrm{kg}$ curing salt (salt containing $0.5 \%$ sodium nitrite), $2.5 \mathrm{~g} / \mathrm{kg}$ tetrasodium phosphate and $0.5 \mathrm{~g} / \mathrm{kg}$ ascorbic acid (Frutarom, Emmerich, Germany).

The meat and fat was firstly minced in a grinder (Mado Primus MEW 603, 1.45 P/kW, Wuppertal, Germany) and then subjected to fine cutting by a cutter (Kilia Vacuum Cooking Bowl Cutter 5000 Express, 7.5 P/kW, Neumünster, Germany) allowing the formation of an emulsion and adding the ingredients and spices after the 
Table 1. Formulations and experimental design.

\begin{tabular}{|cccccccccc}
\hline Batches & Code & \multicolumn{3}{c}{ Ingredients } & \multicolumn{5}{c}{ Total Fat Fat Reduction } \\
\hline & & Meat trimmings & Fatty Tissue & Cheeks & Ice & Oil & \\
\hline Control & & $\mathbf{( \% )}$ & $\mathbf{( \% )}$ & $\mathbf{( \% )}$ & $\mathbf{( \% )}$ & $\mathbf{( \% )}$ & $\mathbf{( \% )}$ & $(\mathbf{\% )}$ \\
\hline Fat reduction 15\% & $\mathbf{C}$ & 50.0 & 15.0 & 20.0 & 15.0 & 0.0 & 24.0 & 0.0 \\
Fat reduction 30\% & $\mathbf{1 A}$ & 56.0 & 9.0 & 20.0 & 15.0 & 0.0 & 20.9 & 15.0 \\
Fat reduction 45\% & $\mathbf{1 B}$ & 62.0 & 3.0 & 20.0 & 15.0 & 0.0 & 17.2 & 30.0 \\
Fat replacement 3\% & $\mathbf{1 C}$ & 65.0 & 0.0 & 20.0 & 15.0 & 0.0 & 15.0 & 45.0 \\
Fat replacement 6.5\% & $\mathbf{2 A}$ & 52.0 & 10.0 & 20.0 & 15.0 & 3.0 & 24.2 & 0.0 \\
Fat replacement 10\% & $\mathbf{2 B}$ & 53.5 & 5.0 & 20.0 & 15.0 & 6.5 & 24.3 & 0.0 \\
Fat replacement 10\% (with emulsifier) & $\mathbf{2 C}+\mathbf{e}$ & 55.0 & 0.0 & 20.0 & 15.0 & 10.0 & 24.4 & 0.0 \\
Fat reduction 30\% and replacement 2\% & $\mathbf{3 A}$ & 63.0 & 0.0 & 20.0 & 15.0 & 2.0 & 17.0 & 30.0 \\
\hline
\end{tabular}

meat (when the olive oil was used it was poured then gently).The last ingredient added was the ice. This process is controlled by the temperature; the first step until it reaches $10^{\circ} \mathrm{C}$ is followed by vacuum cutting until it reaches $13^{\circ} \mathrm{C}$ in order to minimize air incorporation into the emulsion. The next step is the casing in a stuffer (Vemag DP3 Typ 138, Verden, Germany). Synthetic casings of 60 mm diameter (Casetech-Kplus, Walsroder, Germany) were used to reach approximately $1 \mathrm{~kg}$ per sausage. Finally, the sausages were heat treated in a chamber at $78^{\circ} \mathrm{C}$ and when the core temperature reached $72^{\circ} \mathrm{C}$ the sausages were kept for 3 minutes. Finally, they were cooled down with cold water showering. The cooked sausages were labeled and stored at $2.5^{\circ} \mathrm{C}$.

\subsection{Experimental Design}

Bologna type Cooked sausages were formulated to improve the fat fraction in some cases by reducing the fat trimmings added but also by replacing the fat with virgin olive oil (obtained from local supermarket), or even both (Table 1). Eight different recipes were elaborated. A control formulation (C) prepared with 50\% meat trimmings and 15\% fatty tissue content. According to this recipe a 15\% fat reduced sausage was formulated (1A) and also $30 \%$ and $45 \%$ fat reduced sausages (1B and 1C respectively) (Table 1) and then processed following the treatment explained previously. Apart from the fat reduced cooked sausages, sausages with olive oil, as animal fat replacer, were elaborated always following the same elaboration steps. The formulations were calculated to maintain the percentage of total fat as in the control adjusting the percentages of meat trimmings and fatty tissue accordingly (Table 1$)$. The recipe $(2 \mathrm{C}+\mathrm{e})$ corresponded to a product in which an emulsifier was added just in case the emulsion was not appropriate (mono- and di-glyceride 8 g/kg, Frutarom, Emmerich, Germany). The recipe (3A) combined a fat reduction (30\%) with fat replacement by olive oil (2\%).

\subsection{Chemical Analyses}

\subsubsection{Chemical Composition}

Ashes were analyzed according to the method ASU L06.00-4 and for Chloride according to the method ASU L06.00-5). Fat was determined according to German official method "Caviezel” (ASU L06.00-06 and DGF CIII 19).

Salt was analyzed by following German official method L07.00-5/1 (LFGB, 2011). For hydroxyproline following method ASU L06.00-8 was used as a determination of the content of meat protein free of connective tissue protein. The protein content was determined based on the method ASU L06.00-7 and the water by method the L06.00-1. Nitrates were determined by method based on ASU L08.00-14, phosphate by method ASU L06.00-15 and connective tissue by following $\$ 64$ LFGB method. Except for total fat and total protein content, the rest of the chemical components analyzed showed very similar values for all the batches. Salt content was $1.78 \pm 0.02$ (g/100g), nitrates $50.04 \pm 1.80$ (mg/kg), nitrites $39.54 \pm 1.28$ (mg/kg), sodium $822 \pm 4.00$ (mg/100g), chlorine $1.08 \pm 0.01$ (g/100g), connective tissue $1.07 \pm 0.15$ (g/100g), hydroxyproline $0.13 \pm 0.02$ (g/100g) and ashes $2.67 \pm 0.03(\mathrm{~g} / 100 \mathrm{~g})$. 


\subsubsection{Lipid Oxidation}

The extent of lipid oxidation was measured by the peroxide value and thiobarbituric acid reactive substances (TBARS). Peroxide was measured using a titrimetry procedure based on PV 320 method and expressed in mEq/ kg fat. TBARS was measured using the method described by Jensen, Skibsted, Jacobsen, \& Bertelsen (1995) [17]. TBARS were expressed as mg malondialdehyde/kg meat. The values were the means of two different measurements of two different parts of the samples exposed to the same treatment.

\subsubsection{Fatty Acids Analysis}

Fatty acid profile is obtained by methylation of the fatty acid followed by gas chromatography analysis. The method is according to DGF C-VI 11d (1986) [18].

\subsection{Physical Analysis}

\subsubsection{Color}

Color measurements $\left(L^{*}, a^{*}, b^{*}\right.$ values) were carried out in order to track intensity of color changes. For one measuring point, 5 samples were taken and measured per triplicate under same environmental conditions using the Minolta spectrophotometer CM 700d (Konica Minolta GmbH, Germany) and the standard light D65. The results were compared with the control using the index $\Delta E_{a b}{ }^{*}$ which is calculated using the Equation (1).

Equation (1):

$$
\Delta E_{a b}^{*}=\sqrt{\left(L_{2}^{*}-L_{1}^{*}\right)^{2}+\left(a_{2}^{*}+a_{1}^{*}\right)^{2}+\left(b_{2}^{*}+b_{1}^{*}\right)^{2}}
$$

where, $L_{2}^{*}$ means brightness for the sample and $L_{1}^{*}$ brightness for the control, $a_{2}^{*}$ means redness for the sample and $a_{1}^{*}$ redness for control and $b_{2}^{*}$ means yellowness for the sample and $b_{1}^{*}$ yellowness for the control.

The result are interpreted as follows: a value of $\Delta E_{a b}{ }^{*}$ between 0 - 1 means no color differences between control and sample, 1 - 2 means that there is only a slight color difference (trained eye), 2 - 4 stands for a detectable color difference, 4 - 5 for an intensive color difference and $>5$ for a very intensive color difference.

\subsubsection{Texture}

Rectangular blocks ( $2 \mathrm{~cm}$ height $\times 2 \mathrm{~cm}$ width) were cut from the Bologna type cooked sausages. Cut resistance of the cooked sausage was determined by a texture analyzer (type TA-XT2, Stable Micro Systems Ltd., UK). Measuring parameters were as follows: test speed $(2 \mathrm{~mm} / \mathrm{s})$ and test distance $(30.0 \mathrm{~mm})$.Force resistance of the cooked sausage against the razor blade was recorded during lowering the blade. Maximum force during the cutting process was registered as a parameter for description of cooked sausage cut resistance. The measurements were performed five times per batch.

\subsubsection{Water Holding Capacity}

The water holding capacity (WHC) was determined by calculating the drip loss of the cooked sausage according to the method by Tintchev et al. [19]. Briefly, slices of cooked sausage $(1 \times 2 \mathrm{~cm})$ were placed between two filter papers previously weighted and then a force of $5 \mathrm{~kg}$ was applied onto the sample for five minutes. After that, the weight of the filter paper was measured again. By weight difference before and after the pressing operation the drip loss is calculated. Triplicate samples were measured per batch.

\subsection{Sensorial Analysis}

Based on the physical-chemical analyses, four recipes (1C, 2B, 2C and 3A) were chosen for the sensorial analysis apart from the control (C). As the purpose of the project was to reduce the fat content, the product $1 \mathrm{C}$ from the group of fat reduced samples, which is the most reduced (45\% fat reduction), was selected for the sensorial analysis. Cooked sausages, 2B and 2C, were selected for the same reason as they represented the higher fat replacement by olive oil. And finally, 3A was chosen to evaluate a sample that combines fat reduction and replacement in a single sample.

The first sensory evaluation was performed in order to determine the samples that consumers consider as better regarding the attributes mentioned below. A Friedman test was carried out. The sensory trials were carried out in a room with cabinets with controlled illumination at room temperature. The samples were cut in slices of 
$2 \mathrm{~mm}$ thickness and offered to the panelists in small white plastic cups numbered with random numbers of three digits after 17 days of storage under refrigeration $\left(2^{\circ} \mathrm{C}-4^{\circ} \mathrm{C}\right)$. The panelists were asked to evaluate the appearance, smell, texture and flavor in order to rank the five samples (C, 1C, 2B, 2C, 3A) in a scale from "Dislike" to "Like". The sensorial analysis was interpreted using the Friedman test [ISO 8587, 1988 (E)]. Briefly, a number from 1 to 5 was assigned to each sample according to its position in the scale and the average was calculated to compare the samples in the ranking for each attribute. The sum of the results of each of the samples for each attribute is subtracted from the sum of the results of the sample considered the worst. The result was compared with the value from tables according to $5 \%$ and $1 \%$ of significance.

Considering these results, a second sensory trial test was carried out. A triangle test was carried out to ascertain differences between the reference cooked sausage (C) and the developed formulation with higher aceptabilities; $1 \mathrm{C}$ and 2B. In a triangel test, two samples are the same and one is different. Different random numbers were given to all the samples. Three triangle tests (C-1C, C-2B and $1 \mathrm{C}-2 \mathrm{~B})$ was performed asking about the flavour and texture differences.

\subsection{Statistical Analyses}

Data collected for water holding capacity, texture analysis, protein and fat content and colour analyses were analyzed by one-way analyses of variance (ANOVA) to evaluate the statistical significance among the samples, using the PAST program (Version 2.17b, Hammer and Harper 1999-2012).

\section{Results and Discussion}

\subsection{Colour}

The colour values $\left(L^{*}, a^{*}\right.$ and $\left.b^{*}\right)$ for the control and the developed fat reduced and fat replaced Bologna type cooked sausages can be visualized in the Table 2.

Comparing the samples with the control by $\Delta E^{*}$ evaluation, we can conclude that the sample which showed the highest difference was 1C (45\% fat reduced) (Figure 1). As we expected and according to the results of the $a^{*}$ value (Table 2), this difference is likely caused by the higher amount of myoglobin as a result of the substitution of fat by meat what gives to the sausage a redder color and thus an significantly increased $a^{*}$ value is observed (Table 2). Samples 2C and 2C + e which were equivalent except for the emulsifier used on the second one, showed also intensive color differences comparing with the control (Figure 1), showing the highest levels for $b^{*}$ value (Table 2) but also the highest levels for $L^{*}$ value (Table 2). That may be caused by the content of olive oil, raised up to $10 \%$ in both recipes. Apart from those three samples only $1 \mathrm{~B}$ may show detectable color differences also regarding the red color but the rest do not show relevant differences according to the $\Delta E^{*}$ evaluation (Figure 1).

\subsection{Texture}

The results of the texture analysis are expressed as the cutting force required to cut the sample and are showed in the Table 3.

Table 2. Effect of fat reduction and replacement by olive oil on colour of Bologna type cooked sausage.

\begin{tabular}{|c|c|c|c|}
\hline \multirow[t]{2}{*}{ Batches $^{\mathrm{a}}$} & \multicolumn{3}{|c|}{ Color $^{\mathrm{b}}$} \\
\hline & $L^{*}$ & $a^{*}$ & $b^{*}$ \\
\hline C & $75.47 \pm 0.72^{\mathrm{a}, \mathrm{d}}$ & $7.12 \pm 0.20^{c}$ & $8.41 \pm 0.48^{\mathrm{e}}$ \\
\hline $1 \mathrm{~A}$ & $74.70 \pm 0.97^{\mathrm{a}}$ & $7.38 \pm 0.20^{\mathrm{a}, \mathrm{c}}$ & $7.95 \pm 0.38^{\mathrm{a}, \mathrm{d}}$ \\
\hline 1B & $72.52 \pm 0.42^{\mathrm{b}}$ & $7.67 \pm 0.29^{\mathrm{a}}$ & $7.63 \pm 0.17^{\mathrm{a}}$ \\
\hline $1 \mathrm{C}$ & $70.71 \pm 0.36^{\mathrm{c}}$ & $8.68 \pm 0.29^{b}$ & $7.98 \pm 0.43^{\mathrm{a}, \mathrm{d}}$ \\
\hline $2 \mathbf{A}$ & $74.52 \pm 0.59^{\mathrm{a}}$ & $7.30 \pm 0.22^{\mathrm{c}}$ & $9.32 \pm 0.25^{\mathrm{b}}$ \\
\hline 2B & $76.01 \pm 0.69^{\mathrm{d}}$ & $6.55 \pm 0.30^{\mathrm{d}}$ & $9.63 \pm 0.40^{\mathrm{b}}$ \\
\hline $2 \mathrm{C}$ & $75.96 \pm 0.54^{\mathrm{d}}$ & $6.21 \pm 0.22^{\mathrm{e}}$ & $10.53 \pm 0.12^{\mathrm{c}}$ \\
\hline $2 C+e$ & $76.37 \pm 0.75^{d}$ & $5.77 \pm 0.32^{f}$ & $10.20 \pm 0.45^{c}$ \\
\hline 3A & $73.42 \pm 0.76^{\mathrm{b}}$ & $7.20 \pm 0.22^{\mathrm{c}}$ & $8.34 \pm 0.40^{\mathrm{d}, \mathrm{e}}$ \\
\hline
\end{tabular}

${ }^{\mathrm{a}}$ Batches are defined in Table 1. ${ }^{\mathrm{b}}$ Different superscripts within the same column mean significant difference at p-value $<0.05$. 


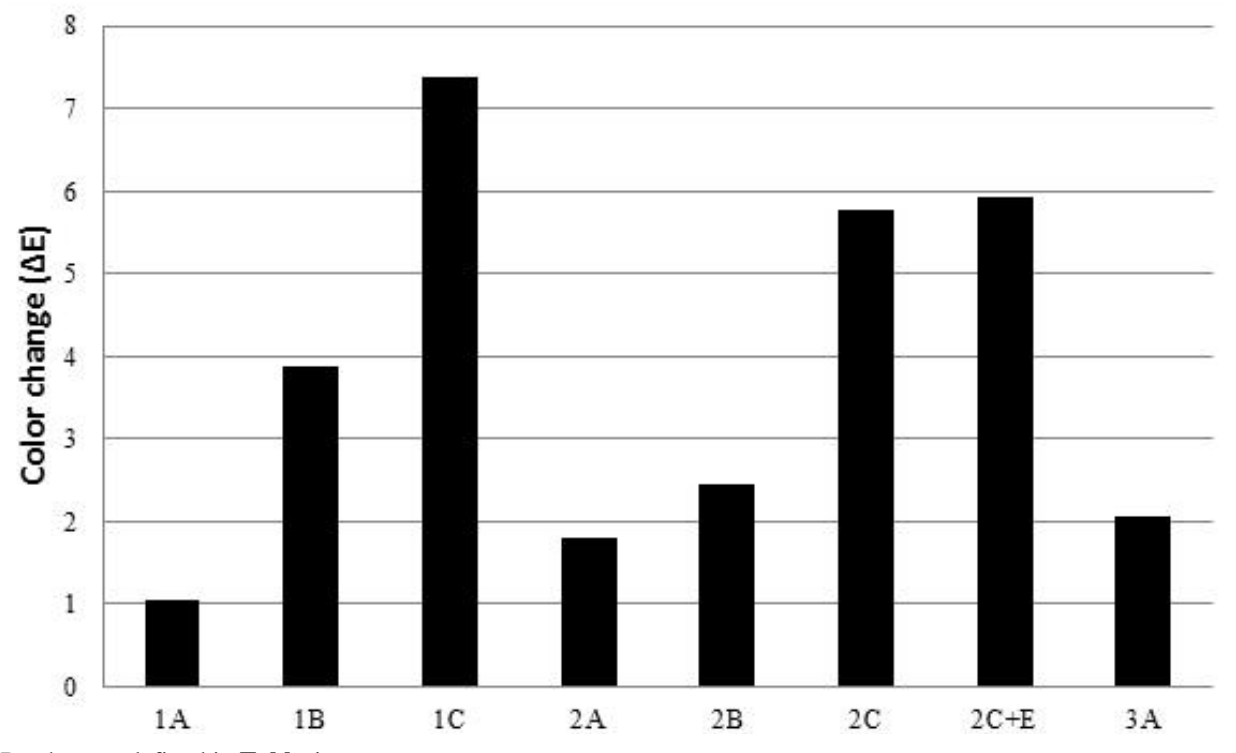

Batches are defined in Table 1.

Figure 1. Effect of fat reduction and replacement by olive oil on overall colour change compared to control sample $(\Delta E)$ of Bologna type cooked sausage.

Table 3. Effect of fat reduction and replacement by olive oil on water holding capacity measured as drip loss and texture measured as cutting force of Bologna type cooked sausage.

\begin{tabular}{|c|c|c|}
\hline Batches $^{a}$ & Cutting force ${ }^{b}$ & Drip loss $^{\text {bc }}$ \\
\hline & $\left(\mathrm{mN} / \mathrm{mm}^{2}\right)$ & (\%) \\
\hline C & $11.43 \pm 0.24^{\mathrm{a}}$ & $16.10 \pm 0.43^{\mathrm{a}, \mathrm{c}, \mathrm{d}}$ \\
\hline $1 \mathrm{~A}$ & $11.78 \pm 0.29^{\mathrm{a}}$ & $10.97 \pm 1.21^{\mathrm{b}, \mathrm{c}}$ \\
\hline 1B & $14.88 \pm 0.61^{\mathrm{b}, \mathrm{d}}$ & $17.37 \pm 1.58^{\mathrm{a}, \mathrm{d}}$ \\
\hline $1 \mathrm{C}$ & $14.06 \pm 0.65^{\mathrm{b}, \mathrm{c}, \mathrm{d}}$ & $16.77 \pm 1.48^{\mathrm{a}, \mathrm{d}}$ \\
\hline $2 A$ & $15.41 \pm 0.86^{\mathrm{b}, \mathrm{d}}$ & $16.31 \pm 1.04^{\mathrm{a}, \mathrm{c}, \mathrm{d}}$ \\
\hline $2 B$ & $13.26 \pm 0.63^{\mathrm{a}, \mathrm{c}, \mathrm{d}}$ & $12.38 \pm 1.13^{\mathrm{a}, \mathrm{c}, \mathrm{d}}$ \\
\hline $2 \mathrm{C}$ & $16.02 \pm 0.66^{\mathrm{b}}$ & $13.54 \pm 0.55^{\mathrm{c}, \mathrm{b}, \mathrm{c}}$ \\
\hline $2 C+e$ & $12.44 \pm 1.15^{\mathrm{a}, \mathrm{c}}$ & $11.13 \pm 0.89^{b}$ \\
\hline $3 A$ & $13.86 \pm 0.93^{\mathrm{d}, \mathrm{c}}$ & $15.63 \pm 0.71^{\mathrm{d}}$ \\
\hline
\end{tabular}

${ }^{\mathrm{a}}$ Batches are defined in Table 1. ${ }^{\mathrm{b}}$ Different superscripts within the same column mean significant difference at p-

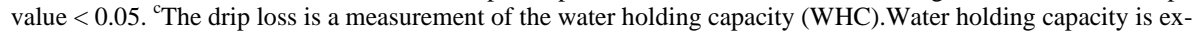
pressed as drip loss (\%).

The samples which showed the maximal hardness were 1B (30\% fat reduction), 1C (45\% fat reduction), $2 \mathrm{~A}$ (3\% olive oil) and 2C (10\% olive oil). It appears than modification of the formulation can lead to modification of the texture by increasing the protein content (1B and $1 \mathrm{C}$ ) or the replacement of the animal fat by olive oil (2A and 2C) According to the statistical analyses the samples most similar to the control regarding the texture were sample $1 \mathrm{~A}$ (15\% fat reduction), sample $2 \mathrm{~B}(6.5 \%$ olive oil) as well as $2 \mathrm{C}+\mathrm{e}(10 \%$ olive oil + emulsifier) (Table 2). Overall, it is difficult to conclude clear statements about the relationship between fat reduction and replacement by using olive oil as a fat replacer with a harder or softer texture comparing with the control since no relationships have been found among all the samples from the same group, considering two groups as fat reduced samples group and fat replaced samples group (Table 3).

The influence on the texture is obvious for the samples mentioned before, but less so are the reasons behind these observed differences, not even inside the group of samples which were fat replaced an expected rise or decrease regarding a higher percent of olive oil can be appreciated. The structure formation of an emulsified sausage is rather complex event and depends on multiple factors. The modification of protein content, fat content and fat profile has a decisive impact on the interface protein-fat of the emulsion and further gelification and therefore can affect structure formation and texture in this way. 


\subsection{Water Holding Capacity}

According to previous studies, as the percentage of fat increases, the percentage of water decreases. There is also a strong correlation between protein and water [20]. The content of fat in meat affects the water holding capacity (WHC) because it is non-polar and it decreases the amount of protein available for attracting and holding water. The similarities among the samples found by the statistical analysis are shown in Table 3 . According to our results, less drip loss happens when olive oil is used as a fat replacer (samples 2B, 2C and 2C + e) but also animal fat may favor the WHC although a higher protein content, which also means higher water content, showed higher drip losses (1A compared to 1B and 1C, Table 3).

Regarding sample 3A which combines fat reduction and $2 \%$ of animal fat replaced by olive oil, it showed better WHC than the samples only fat reduced, what is in agreement with the higher drip loss observed in samples fat reduced (1B and $1 \mathrm{C}$ ) or could indicate that olive oil improves the water binding in these products.

Nevertheless, the standard deviation of several samples turns out to be too high to consider the results as clear and statistically significant. The modification of protein and fat content as well as the degree of unsaturation of the fat is playing a role in the structure formation and thus in the final texture and water holding capacity of the Bologna type cooked sausage. The water binding is the result of the history and processing of the meat and others parameters such as the slaughtering or even genetic factors might have an influence on the products as well [20].

\subsection{Chemical Analyses}

\subsubsection{Fat and Protein Content}

Depending on the ingredients of the different formulations, expected differences were confirmed regarding protein and fat contents (Figure 2).

Related to the fat content, important differences can be observed between the control and the fat reduced samples (especially for samples 30\% and $45 \%$ fat reduced, $1 \mathrm{~B}$ and $1 \mathrm{C}$ ) as well as the sample 3A, which was fat reduced (30\%) and replaced with $2 \%$ of olive oil (3A) (Figure 2). Control (C) is similar to the fat replaced samples (2A and $2 \mathrm{~B}$ ), and obviously $2 \mathrm{C}$ and $2 \mathrm{C}+\mathrm{e}$ did not show differences because the formulation was exactly the same except the emulsifier used in $2 \mathrm{C}+\mathrm{e}$.

Regarding protein content, the different samples sited in a much more tight rank in comparison to the rank for fat content. Samples 1A and 2A were similar to control and among them, as well as 1A, 2A, 2B, 2C and 2C + e. Sample 1C was the one with highest protein content because of the use of meat as fat replacer, which was similar to $1 \mathrm{~B}$ and $3 \mathrm{~A}$ (Figure 2).

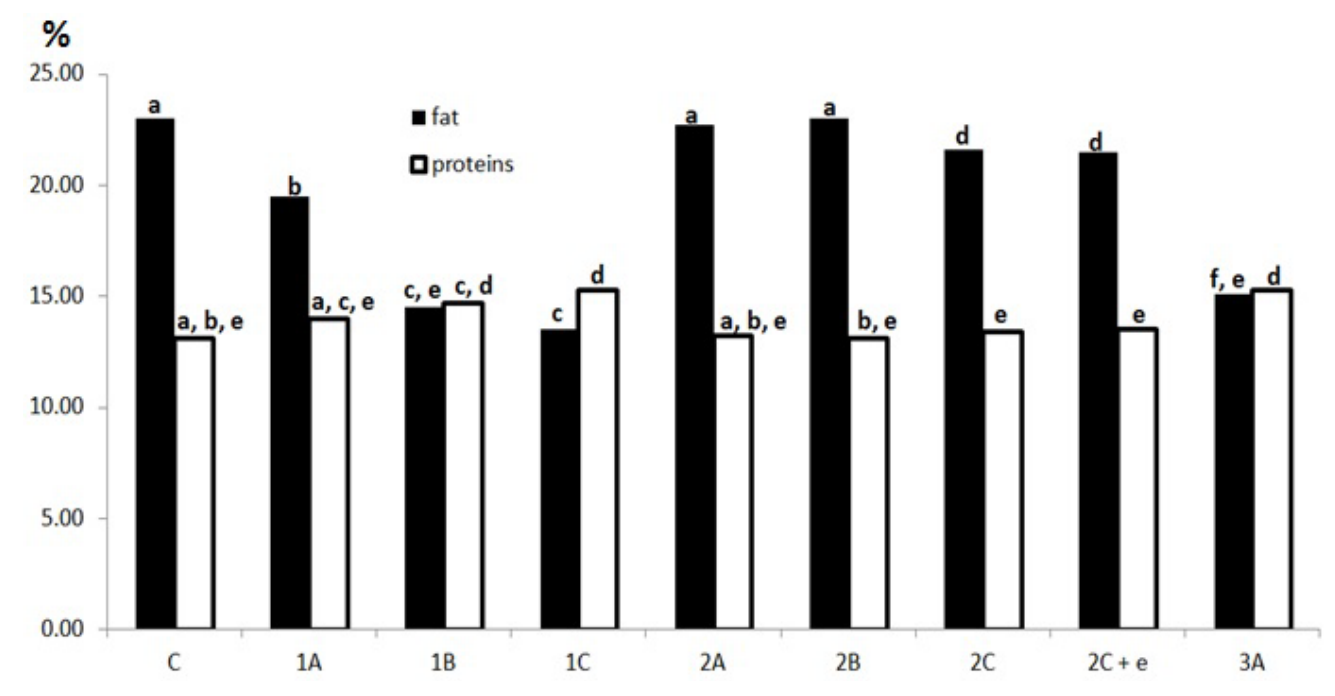

Black filled columns stand for fat and black border for protein. Batches are defined in Table 1. Different superscripts for the same parameter (fat or protein) mean significant difference at p-value $<0.05$.

Figure 2. Effect of fat reduction and replacement by olive oil on protein and fat content (\%) of Bologna type cooked sausage. 


\subsubsection{Fat Oxidation}

The fat oxidation was analyzed measuring primary oxidation compounds (i.e. peroxides) and secondary oxidation compounds (i.e. TBARS) at 15 days and 30 days refrigerated storage $\left(2^{\circ} \mathrm{C}-4^{\circ} \mathrm{C}\right)$ (Table 4$)$.

No important differences were found between the samples. Nevertheless, it could be highlighted that the samples which contained olive oil showed slightly higher levels of oxidation (Table 4). Olive oil has a more unsaturated fat than pork fat, the former being more prone to oxidation. Even though, the levels of oxidation are considered rather low (limits for unacceptable products are10 mEq/kg fat for peroxide value [21] and $1-1.5 \mathrm{mg} / \mathrm{kg}$ for TBARS value [22] [23].

\subsubsection{Saturated Fatty Acids (SFA)}

The percentage of saturated fatty acids (g/100g fat) is lower when the animal fat is replaced by olive oil (Table 5). The differences are clearly shown on samples with $10 \%$ oil $(2 \mathrm{C}$ and $2 \mathrm{C}+\mathrm{e})$ by comparison of the value of the sample 1C (45\% fat reduced) with the ones with olive oil. It can be concluded that replacing animal fat by olive oil, the saturated lipid profile improves. This is also confirmed later on as for the lipid nutritional indexes (3.4.5). Regarding the total saturated fatty acids in the final product, the lowest levels are shown for the fat reduced samples including the sample $3 \mathrm{~A}$ which is fat replaced and reduced. The highest content of saturated fat is shown at the control.

\subsubsection{Unsaturated Fatty Acids}

The most important unsaturated fatty acid in olive oil is oleic acid and as the results show, the samples having

Table 4. Effect of fat reduction and replacement by olive oil on fat oxidation upon storage 15 and 30 days in chilling conditions measured by peroxide value and TBARS value after of Bologna type cooked sausage.

\begin{tabular}{|c|c|c|c|c|}
\hline \multirow[t]{3}{*}{ Batches $^{\mathrm{a}}$} & \multicolumn{4}{|c|}{ Time } \\
\hline & \multicolumn{2}{|c|}{15 day } & \multicolumn{2}{|c|}{30 day } \\
\hline & Peroxide value & TBARS value & Peroxide value & TBARS value \\
\hline & (mEq/kg fat) & (mg MDA/kg) & (mEq/kg fat) & (mg MDA/kg) \\
\hline $\mathrm{C}$ & $<1.00^{\mathrm{b}}$ & 0.05 & $<1.00$ & 0.03 \\
\hline $\mathbf{1 A}$ & $<1.00$ & 0.05 & $<1.00$ & 0.04 \\
\hline $1 B$ & $<1.00$ & 0.05 & $<1.00$ & 0.04 \\
\hline $1 \mathrm{C}$ & $<1.00$ & 0.05 & $<1.00$ & 0.04 \\
\hline $2 A$ & $<1.00$ & 0.06 & 1.26 & 0.05 \\
\hline 2B & 3.38 & 0.09 & 1.63 & 0.06 \\
\hline $2 \mathrm{C}$ & 3.39 & 0.09 & 1.87 & 0.07 \\
\hline $2 C+e$ & 3.61 & 0.25 & 3.44 & 0.20 \\
\hline 3A & $<1.00$ & 0.20 & 1.48 & 0.19 \\
\hline
\end{tabular}

${ }^{\mathrm{a}}$ Batches are defined in Table 1. ${ }^{\mathrm{b}}$ Detection limit.

Table 5. Effect of fat reduction and replacement by olive oil on saturated fatty acids (SFA) content of Bologna type cooked sausage.

\begin{tabular}{|c|c|c|c|c|c|c|c|}
\hline \multirow[t]{2}{*}{ Batches $^{a}$} & \multicolumn{7}{|c|}{ Saturated Fatty Acids } \\
\hline & Lauric & Myristic & Pentadecilic & Palmitic & Margaric & Stearic & Total SFA \\
\hline & \multicolumn{6}{|c|}{ (g/100g fat) } & (g/100g product) \\
\hline $\mathbf{C}$ & 0.16 & 1.61 & 0.13 & 23.60 & 0.32 & 12.20 & 8.87 \\
\hline $1 \mathrm{~A}$ & 0.16 & 1.71 & 0.14 & 24.30 & 0.33 & 12.00 & 7.62 \\
\hline $1 B$ & 0.16 & 1.75 & 0.19 & 24.90 & 0.37 & 11.80 & 5.75 \\
\hline $1 \mathrm{C}$ & 0.16 & 1.72 & 0.20 & 24.90 & 0.38 & 12.00 & 5.38 \\
\hline $2 A$ & 0.14 & 1.46 & 0.12 & 22.60 & 0.31 & 10.90 & 8.17 \\
\hline 2B & 0.12 & 1.23 & 0.11 & 20.90 & 0.28 & 9.61 & 7.53 \\
\hline $2 \mathrm{C}$ & $<0.10$ & 0.92 & 0.10 & 18.80 & 0.23 & 7.83 & 6.17 \\
\hline $2 C+e$ & $<0.10$ & 0.89 & 0.11 & 18.70 & 0.23 & 9.70 & 6.54 \\
\hline 3A & 0.14 & 1.48 & 0.18 & 22.40 & 0.32 & 10.30 & 5.34 \\
\hline
\end{tabular}

${ }^{\mathrm{a}}$ Batches are defined in Table 1. 
the higher content of olive oil also have the higher content of oleic acid (especially comparing control and fat reduced samples to 2B and 2C cooked sausages) (Table 6). The percentage of monounsaturated fatty acids (MUFA)in the final product is almost double in the samples which contain olive oil (2A, 2B, 2C and 2C + e) comparing with the fat reduced samples (1B and 1C).Regarding polyunsaturated fatty acids (PUFA),their percentage are not strongly affected by the addition of olive oil. It seems that they are not provided by the olive oil but by the animal fat that is the reason for the control to show higher content than the ones with olive oil or the fat reduced samples.

\subsubsection{Lipid Nutritional Indexes}

Several nutrition organisations recommend on our diet not only a certain limitation of fat intake but also a balance between the saturated and the unsaturated fatty acids [24] [25].

According to the results, it is confirmed that the lipid nutritional index PUFA + MUFA/SFA is improved by the addition of olive oil (Table 7). The addition of a percentage of olive oil above 6.5\% (corresponding to sample 2B) achieved the nutritional recommendations ((PUFA + MUFA)/SFA $\geq 2.00)$. Another lipid index which also assessed the balance of the fatty acid is considered only the polyunsaturated fat (i.e. PUFA/SFA). In this case, only one of the samples gets closer to the recommendations, the one with the highest content of olive oil (10\%) (Table 7).

Table 6. Effect of fat reduction and replacement by olive oil on unsaturated fatty acids content of Bologna type cooked sausage.

\begin{tabular}{|c|c|c|c|c|c|c|c|c|c|}
\hline \multirow[t]{2}{*}{ Batches $^{a}$} & \multicolumn{9}{|c|}{ Unsaturated Fatty Acids } \\
\hline & Palmitoleic & Oleic & Linoleic & Eicosenoic & Arachidonic & Erucic & Docosapentanoic & Total MUFA & Total PUFA \\
\hline & \multicolumn{7}{|c|}{ (g/100g fat) } & \multicolumn{2}{|c|}{ (g/100g product) } \\
\hline C & 2.77 & 43.60 & 11.90 & 0.86 & 0.43 & 0.15 & 0.11 & 10.90 & 3.22 \\
\hline $1 \mathbf{A}$ & 2.92 & 42.70 & 12.10 & 0.81 & 0.47 & 0.14 & 0.12 & 9.10 & 2.78 \\
\hline $1 B$ & 3.08 & 42.40 & 11.70 & 0.78 & 0.56 & 0.13 & 0.13 & 6.73 & 2.02 \\
\hline $1 \mathrm{C}$ & 3.02 & 42.30 & 11.70 & 0.77 & 0.57 & 0.13 & 0.13 & 6.24 & 1.88 \\
\hline $2 \mathrm{~A}$ & 2.63 & 46.80 & 11.70 & 0.76 & 0.39 & 0.13 & 0.10 & 11.40 & 3.10 \\
\hline $2 B$ & 2.36 & 51.10 & 11.10 & 0.69 & 0.36 & 0.10 & $<0.10$ & 12.50 & 2.97 \\
\hline $2 \mathrm{C}$ & 2.08 & 56.50 & 10.60 & 0.61 & 0.33 & $<0.10$ & $<0.10$ & 12.80 & 2.63 \\
\hline $2 C+e$ & 2.00 & 55.30 & 10.00 & 0.59 & 0.32 & $<0.10$ & $<0.10$ & 12.50 & 2.48 \\
\hline $\mathbf{3 A}$ & 2.73 & 47.50 & 11.50 & 0.72 & 0.52 & 0.12 & 0.11 & 7.72 & 2.04 \\
\hline
\end{tabular}

${ }^{\mathrm{a}}$ Batches are defined in Table 1.

Table 7. Effect of fat reduction and replacement by olive oil on the lipid nutritional indexes (polyunsaturated fatty acids and monunsaturated (PUFA + MUFA)/saturated fatty acids (SFA) and (PUFA/SFA) of Bologna type cooked sausage.

\begin{tabular}{ccc}
\hline Bacthes $^{\mathbf{a}}$ & \multicolumn{2}{c}{ Lipid nutritional indexes } \\
\hline $\mathbf{C}$ & (PUFA + MUFA)/SFA $^{\text {(PUFA/SFA) }}$ \\
$\mathbf{1 A}$ & 1.59 & 0.36 \\
$\mathbf{1 B}$ & 1.56 & 0.36 \\
$\mathbf{1 C}$ & 1.52 & 0.35 \\
$\mathbf{2 A}$ & 1.51 & 0.35 \\
$\mathbf{2 B}$ & 1.77 & 0.38 \\
$\mathbf{2 C}$ & 2.05 & 0.39 \\
$\mathbf{2 C}+\mathbf{e}$ & 2.50 & 0.43 \\
3A & 2.29 & 0.38 \\
Recommendation & 1.83 & 0.38 \\
\hline
\end{tabular}

${ }^{\mathrm{a}}$ Batches are defined in Table 1. 


\subsubsection{Energy Content}

Another important point regarding healthy aspects is the energy on our diet as well as the origin of these calories. For this reason the caloric content was calculated per sample considering $4 \mathrm{kcal} / \mathrm{g}$ for the protein and $9 \mathrm{kcal} / \mathrm{g}$ for fat.

The Table 8 shows the caloric content of the different formulations of Bologna type cooked sausage produced. The caloric content of the control was $259.4 \mathrm{kcal} / \mathrm{g}$. The highest difference to the control was for the sample with the highest fat reduction $(45 \%, 182.7 \mathrm{kcal} / \mathrm{g})$. This represents aproximately a $30 \%$ reduction in caloric content. Although sample 2B (6.5\% oil) has the same calories as the control, the fatty acid relation (PUFA + MUFA/SFA) is more appropriate, as it was explained before.

\subsection{Sensory Evaluation}

Bologna type cooked sausages C, 1C, 2B, 2C, 3A were ordered in a scale from 1, "Dislike”, to 5, "Like”, for the appearance, smell, texture and flavor. Only regarding the general appearance there were significant differences (p-value < 0.01). The sample 1C (45\% fat reduced) was considered as the best and 2C (10\% olive oil) as the worst. We believe that these results were due to the high content of myoglobin on sample $1 \mathrm{C}$; the redder the product was, the best acceptation. In relation to the rest of the attributes, there were not statistically significant differences although, sample $2 \mathrm{C}$ and $\mathrm{1C}$ were always considered as the worst and the best, respectively, regarding the rest attributes.

Previous results are about the comparison of the whole ranking but also two individual samples can be compared. In this case, each sample is compared with the one considered as the worst which was 2C. There were significant differences regarding the appearance between sample 2C and $\mathrm{C}$ (p-value $<0.05$ ) as well as 2C and $3 \mathrm{~A}$, and 2C and 1C (both p-value $<0.01$ ). Regarding the smell there were significant differences only when sample 2C and 1C were compared (p-value $<0.05$ ) and no significance differences regarding the texture or flavour were detected.

Considering these results, a second sensory trial test (triangle test) was carried out in order to show if the panellists could find the differences among the samples that they had considered as the best (1C and 2B) in comparison with the reference sample (C, control). Regarding the taste, panellists found that samples $1 \mathrm{C}$ and $2 \mathrm{~B}$ are significantly different to the control ( $\mathrm{p}$-value $<0.01$ ). In addition, panellist also found sample $1 \mathrm{C}$ compared to 2B significantly different (p-value $<0.01$ ). Regarding the texture, control and sample $1 \mathrm{C}$ were found significantly different (p-value $<0.01$ ) but not the comparison of samples control and 2B. Samples 1C and 2B were found significantly different at $99.9 \%$ of significance (p-value $<0.01$ ). Furthermore related to the flavour, the panellists found that sample 1C compared to the control were significantly different with a $99.9 \%$ of significance (p-value $<0.01$ ), and the same was observed for the comparison of control to sample 2B. Comparing the samples $2 \mathrm{~B}$ and $1 \mathrm{C}$, panellists also found them different ( $\mathrm{p}$-value $<0.01$ ).

Overall, panellists were able to differ sensorially control sample (C) of reduced (1C) or replaced (2B) cooked

Table 8. Effect of fat reduction and replacement by olive oil on protein, fat and energy content from fat and protein of Bologna type cooked sausage.

\begin{tabular}{|c|c|c|c|c|c|}
\hline Batches $^{\text {a }}$ & Protein & Fat & Protein & Fat & Total \\
\hline & \multicolumn{2}{|c|}{$(\%)$} & \multicolumn{3}{|c|}{ (kcal/100g) } \\
\hline C & 13.1 & 23.0 & 52.4 & 207.0 & 259.4 \\
\hline $\mathbf{1 A}$ & 14.0 & 19.5 & 56.0 & 175.5 & 231.5 \\
\hline $1 B$ & 14.7 & 14.5 & 58.8 & 130.5 & 189.3 \\
\hline $1 \mathrm{C}$ & 15.3 & 13.5 & 61.2 & 121.5 & 182.7 \\
\hline $2 A$ & 13.2 & 22.7 & 52.8 & 204.3 & 257.1 \\
\hline $2 B$ & 13.1 & 23.0 & 52.4 & 207.0 & 259.4 \\
\hline $2 \mathrm{C}$ & 13.4 & 21.6 & 53.6 & 194.4 & 248.0 \\
\hline $2 C+e$ & 13.5 & 21.5 & 54.0 & 193.5 & 247.5 \\
\hline 3A & 15.3 & 15.1 & 61.2 & 135.9 & 197.1 \\
\hline
\end{tabular}

${ }^{\mathrm{a} B a t c h e s}$ are defined in Table 1. 
sausages as well as reduced from replaced cooked sausage. However, sample 1C (45\% fat reduction) was considered in the first sensory test as better than the control and sample 2B (6.5\% olive oil) also was perceived as good for the consumers. In contrast, sample $2 \mathrm{C}$ (10\% of olive oil) obtained a lower appreciation by the consumers indicating that percentages of fat replacement by olive oil above $6.5 \%$ can impar product quality and therefore needs further modifications in the formulation or the processing (for instance adjustment of the cooked sausage color). In agreement with our conclusions, other studies have also found that reduced fat Bologna mortadella had higher or similar consumer acceptability than the traditional product, considering a $66 \%$ fat reduction as an alternative in the market [26].

\subsection{Cost Estimation}

A calculation of the costs for the different formulations was done taking into account only the costs of the raw meats (Table 9).

This calculation is valid and assumes that costs of other ingredients and additives as well as processing were the same in all cases. It can be observed that recipes fat reduced $(1 \mathrm{~A}, 1 \mathrm{~B}$ and $1 \mathrm{C})$ become more expensive because of the addition of higher proportions of lean meat. Also the replacement of fatty tissue by olive oil has associated an increase in price. This increase in price is approximately between $5 \%-15 \%$ due to the increased costs of the raw materials. As other scientific studies have indicated, total animal fat can be reduced without causing a major impact in terms of the price [27]. Nevertheless, the use of plant oils instead of animal fat results not only in a healthier product but also a more sustainable product. Different authors have emphasized the inclusion of plant oils in the formulations of healthier meat products [28] which in addition are accompanied with a reduction of meat consumption and contribute to the establishment of more efficient meat production systems for a sustainable world [29].

\section{Conclusion}

Fat reduction and replacement by olive oil are alternatives to develop healthier meat products. Out of all the Bologna type cooked sausages assayed, the cooked sausage having 45\% fat reduction(1C) had the lower caloric content and the cooked sausage having $10 \%$ of olive oil (replacing fatty tissue) (2C) had the best lipid profile. In addition, it is reported that the cooked sausage with $45 \%$ of fat reduction (1C) was considered as the best for the panelists according to the appearance, texture, flavor and smell. On the contrary, the sample $2 \mathrm{C}$ having the highest percentage of olive oil (10\%) was considered as the worst regarding all sensorial attributes evaluated. Furthermore, Bologna type cooked sausages having $6.5 \%$ of added olive oil as well as the combination of $30 \%$ of fat reduction with the addition of $2 \%$ olive oil showed good lipid profiles and acceptability by the consumers and thus representing realistic strategies to improve the lipid fraction of Bologna type cooked sausage. It can be concluded that relevant fat reduction (up to 45\%) might be applied to Bologna type cooked sausage without compromising sensorial acceptability. This fact can allow labeling these products as "low fat" and having very good sensorial acceptation by the consumers, even better than the control cooked sausages.

Table 9. Effect of fat reduction and replacement by olive oil on estimated cost (euro/kg) of raw meat Bologna type cooked sausage.

\begin{tabular}{|cc|}
\hline Batches $^{\mathbf{a}}$ & $\begin{array}{c}\text { Cost of raw materials } \\
\text { (euro/kg) }\end{array}$ \\
\hline C & 1.92 \\
$\mathbf{1 A}$ & 2.04 \\
$\mathbf{1 B}$ & 2.17 \\
$\mathbf{1 C}$ & 2.23 \\
$\mathbf{2 A}$ & 2.02 \\
$\mathbf{2 B}$ & 2.13 \\
$\mathbf{2 C}$ & 2.23 \\
$\mathbf{2 C}+\mathbf{e}$ & 2.23 \\
$\mathbf{3 A}$ & 2.23 \\
\hline
\end{tabular}

${ }^{\mathrm{a}}$ Batches are defined in Table 1. 


\section{Acknowledgements}

This study was carried out with financial support from the European Commission, FP7, Thematic Area KBBE, Project "PLEASURE” (Grant agreement no: 289536). It does not necessarily reflect its views and in no way anticipates the Commission's future policy in this area.

\section{References}

[1] Gracia, A. and Albisu, L.M. (2001) Food Consumption in the EU: Main Determinants and Country Difference. Agribusiness, 17, 469-488. http://dx.doi.org/10.1002/agr.1030

[2] Salamanca Pérez, O.L. (2012) La Ganadería Colombiana en la Nueva Dinámica del Comercio Internacional. FEDEGAN, Federacion Colombiana de Ganaderos, Bogota (Colombia).

[3] (2012) PLEASURE Project. http://www.pleasure-fp7.com/

[4] Council of the European Union (2006) Council Conclusions on Promotion of Healthy Lifestyles and Prevention of Type 2 Diabetes (2006/C 147/01). Official Journal of the European Union, 23.6.2006 EN C 147, 1-4.

[5] Council of the European Union (2006) Social Policy, Health and Consumer Affairs. 2733rd Employment Council Meeting, Luxembourg, 1-2 June 2006, 28-33.

[6] Nichols, M., Townsand, N., Scarborough, P. and Rayner, M. (2012) European Cardiovascular Disease Statistics. European Heart Network AISBL, 26-33.

[7] WHO (2012) Charting the Way to Well-Being. The European Health Report 2012, World Health Organization, Copenhagen.

[8] Trichopoulou, A., Costacou, T., Bamia, C. and Trichopoulous, D. (2003) Adherence to a Mediterranean Diet and Survival in a Greek Population. The New England Journal of Medicine, 348, 2599-2608. http://dx.doi.org/10.1002/agr.1030

[9] Huang, C.L. and Sumpio, B.E. (2008) Olive Oil, the Mediterranean Diet, and Cardiovascular Health. Journal of the American College of Surgeons, 207, 407-416. http://dx.doi.org/10.1016/j.jamcollsurg.2008.02.018

[10] Covas, M.I., Konstantinidou, V. and Fito, M. (2009) Olive Oil and Cardiovascular Disease. Journal of Cardiovascular Pharmacology, 54, 447-482. http://dx.doi.org/10.1097/FJC.0b013e3181c5e7fd

[11] Ruiz-Canela, M. and Martínez-González, M.A. (2011) Olive Oil in the Primary Prevention of Cardiovascular Disease. Maturitas, 68, 245-250. http://dx.doi.org/10.1016/j.maturitas.2010.12.002

[12] Kesteloot, H., Lesaffre, E. and Joossens, J. (1991) Dairy Fat, Saturated Animal Fat, and Cancer Risk. Preventive Medicine, 20, 226-236. http://dx.doi.org/10.1016/0091-7435(91)90022-V

[13] Krycer, J.R. and Brown, A.J. (2013) Cholesterol Accumulation in Prostate Cancer: A Classic Observation from a Modern Perspective. Biochimicaet Biophysica Acta (BBA)—Reviews on Cancer, 1835, 219-229.

[14] Alawi Alsheikh, A., Trikalinos, T.A., Kent, D.M. and Karas, R.H. (2008) Statins, Low-Density Lipoprotein Cholesterol, and Risk of Cancer. Journal of the American College of Cardiology, 52, 1141-1147. http://dx.doi.org/10.1016/j.jacc.2008.06.037

[15] Pohuang, C., Abraham, N., Stemmermann, G.N. and Kato, I. (1992) Prospective Study of Serum Cholesterol and SiteSpecific Cancers. Journal of Clinical Epidemiology, 45, 287-292. http://dx.doi.org/10.1016/0895-4356(92)90089-6

[16] Christiane, D. and Philippe, F. (2012) Cholesterol and Breast Cancer Development. Current Opinion in Pharmacology, 12, 677-682. http://dx.doi.org/10.1016/j.coph.2012.07.009

[17] Jensen, C., Skibsted, L.H., Jakobsen, K. and Bertelsen, G. (1995) Supplementation of Broiler Diets with all-rac-Alpha- or a Mixture of Natural Sources RRR-Alpha-, Gamma-, Delta-Tocopheryl Acetate II: Effect on the Oxidative Stability of Raw and Precooked Broiler Meat Products. Poultry Science, 74, 2048-2056. http://dx.doi.org/10.3382/ps.0742048

[18] DGF, Deutsche Gessellschaft fur Fettwissenschaft e.V, German Society for Fat Science (1986) Fatty acid Profile. DGF C-VI 11d.

[19] Tintchev, F., Bindrich, U., Toepfl, S., Strijowski, U., Heinz, V. and Knorr, D. (2013) High Hydrostatic Pressure/Temperature Modelling of Frankfurter Batters. Meat Science, 94, 376-387. http://dx.doi.org/10.1016/j.meatsci.2013.02.012

[20] Cheng, Q. and Sun, D.W. (2008) Factors Affecting the Water Holding Capacity of Red Meat Products: A Review of Recent Research Advances. Food Science and Nutrition, 48, 137-159.

[21] BMELV (2013) Leitsätze des Deutschen Lebensmittelbuchs für Speisefette und Speiseöle. http://www.bmelv.de/SharedDocs/Downloads/Ernaehrung/Lebensmittelbuch/LeitsaetzeSpeisefette.html

[22] Martínez, L., Cilla, I., Beltrán, J.A. and Roncalés, P. (2006) Antioxidant Effect of Rosemary, Borage, Green Tea, 
Pu-Erh Tea and Ascorbic Acid on Fresh Pork Sausages Packaged in a Modified Atmosphere: Influence of the Presence of Sodium Chloride. Journal of the Science of Food and Agriculture, 86, 1298-1307. http://dx.doi.org/10.1002/jsfa.2492

[23] Camo, J., Lorés, A., Djenane, D., Beltrán, J.A. and Roncalés, P. (2011) Display Life of Beef Packaged with an Antioxidant Active Film as a Function of the Concentration of Oregano Extract. Meat Science, 88, 174-178. http://dx.doi.org/10.1016/j.meatsci.2010.12.019

[24] WHO (2002) Diet, Nutrition and the Prevention of Chronic Dieases: Report of a Joint WHO/FAO. Expert Consultation (WHO Technical Report Series 916), World Health Organization, Geneva.

[25] Moreiras, O., Carbajal, Á., Cabrera, L. and Cuadrado, C. (2011) Tablas de Composición de Alimentos. 15th Edition, Ediciones Pirámide SA, Madrid.

[26] Spada, F.P., Contreras-Castillo, C.J., Martins, M.M. and Lemos, A.L.C. (2012) Sensory Acceptance of Low-Fat Bologna Mortadella Sausages. 58th International Congress of Meat Science and Technology, Montreal, 12-17 August 2012.

[27] Jiménez-Colmenero, F. (2000) Relevant Factors in Strategies for Fat Reduction in Meat Products. Trends in Food Science and Technology, 11, 55-66

[28] Jiménez-Colmenero, F. (2007) Healthier Lipid Formulation Approaches in Meat-Based Functional Foods. Technological Options for Replacement of Meat Fats by Non-Meat Fats. Trends in Food Science \& Technology, 18, 567-578. http://dx.doi.org/10.1016/j.tifs.2007.05.006

[29] Vinnari, M. (2008) The Future of Meat Consumption-Expert Views from Finland. Technological Forecasting and Social Change, 75, 893-904. http://dx.doi.org/10.1016/j.techfore.2007.02.001 